\title{
Role of APLP2 in the prognosis and clinicopathology of renal cell carcinoma
}

\author{
LIJIAN GAO ${ }^{1,2^{*}}$, HONGDA ZHAO $^{1 *}$, DONGQING ZHANG ${ }^{1}$, CHANGKUO ZHOU $^{1}$, HUI WANG ${ }^{1,2}$, \\ CHANTAO REN ${ }^{2}$, YAXIAO LIU ${ }^{1}$, YANGYANG XIA ${ }^{1}$ and BENKANG SHI ${ }^{1}$ \\ ${ }^{1}$ Department of Urology, Qilu Hospital of Shandong University, Jinan, Shandong 250012; \\ ${ }^{2}$ Department of Urology, Dezhou People's Hospital, Dezhou, Shandong 253000, P.R. China
}

Received December 7, 2017; Accepted September 5, 2018

DOI: $10.3892 / \mathrm{ol} .2018 .9577$

\begin{abstract}
Identifying diagnostic and prognostic biomarkers is crucial for improved guidance of the treatment of renal cell carcinoma (RCC). Amyloid $\beta$ precursor-like protein 2 (APLP2) has been determined to serve an important role in the progression of a number of cancer types. However, the expression and significance of APLP2 in RCC remains unknown. In the present study, it was determined that the expression of APLP2 protein $(n=10)$ and mRNA $(n=8)$ expression was significantly decreased in clear cell RCC (CCRCC) tissues compared with that in matched normal renal tissues. The expression level of APLP2 was significantly associated with high Fuhrman grade, high pT stage, and presence of distant metastasis and lymph node metastasis $(\mathrm{P}<0.05)$. Multivariate analysis demonstrated that the expression of APLP2 was a significant independent predictor of disease-specific survival in renal cell carcinoma $(\mathrm{P}=0.026)$. Notably, APLP2 expression was significantly associated with disease-specific survival $(\mathrm{P}<0.001)$. APLP2 may be used to potentially predict patient prognosis, and to guide clinical diagnosis and treatment in CCRCC.
\end{abstract}

\section{Introduction}

Renal cell carcinoma (RCC) is a common urological malignancy (1). In the USA, an estimated 64,000 new cases of kidney cancer were expected in 2017 (1). Clear cell RCC (CCRCC) represents $70-80 \%$ of RCC cases. In recent years, a number of molecular targeted therapies have been used in the clinical treatment of RCC, but the prognosis remains unfavourable (2). Additionally, predictive biomarkers of response

Correspondence to: Professor Benkang Shi, Department of Urology, Qilu Hospital of Shandong University, 107 Wenhuaxi Road, Jinan, Shandong 250012, P.R. China

E-mail: bkang68@sdu.edu.cn

*Contributed equally

Key words: renal cell carcinoma, amyloid $\beta$ precursor-like protein 2, molecular marker, prognosis have not been identified. Thus, the identification of effective biomarkers is required for predicting the progression and prognosis of RCC, and to advance the development of novel treatments.

Amyloid $\beta$ precursor-like protein 2 (APLP2) is a type I transmembrane protein belonging to the evolutionary conserved amyloid precursor protein gene family, which has been associated with Alzheimer's disease pathogenesis (3). The human APLP2 gene is located at 11q24 and is expressed in the majority of tissues (4). It has been demonstrated that APLP2 expression is involved in the development of a number of cancer types, including pancreatic, colon, breast and prostate cancer (5). APLP2 has been associated with certain characteristics of cancer cells, including abnormal growth, migration and invasion, which indicates that APLP2 may significantly affect the development and progression of cancer (6); however, the expression and function of APLP2 in RCC remains undefined. In the present study, the expression of APLP2 in CCRCC tissues was measured and the association between APLP2 expression and the clinicopathological features of CCRCC was evaluated, in order to determine whether APLP2 may potentially be used as a novel biomarker and therapeutic target for CCRCC.

\section{Materials and methods}

Patients and tumor specimens. All samples were obtained from Qilu Hospital of Shandong University (Jinan, China). The clinical and pathological data of patients (mean, 63; range, 40-81 years of age) who were diagnosed with CCRCC by computed tomography, magnetic resonance imaging and pathological examination, and who underwent surgery between January 2011 and December 2012, were collected upon receiving ethical approval from the Medical Ethics Committee of Qilu Hospital of Shandong University. A total of 90 pairs of tumor and adjacent normal tissues were collected from patients with primary CCRCC. Patients were excluded from the present study if they had missing information. Patients with autoimmune disease or cancer in other systems, and had received neoadjuvant chemotherapy or radiotherapy were also excluded from the present study. Paired CCRCC and adjacent non-tumor tissues were obtained, snap-frozen in liquid nitrogen, and maintained at $-80^{\circ} \mathrm{C}$ until further use. Written informed 
consent was obtained from all subjects. Resected tissues were immediately snap-frozen in liquid nitrogen and stored at $-80^{\circ} \mathrm{C}$ prior to protein and mRNA extraction. Additionally, tissues were fixed for immunohistochemical staining. The present study was approved by the Medical Ethics Committee of Qilu Hospital of Shandong University.

Reverse transcription-quantitative polymerase chain reaction $(R T-q P C R)$. The total RNA from $50 \mathrm{mg}$ frozen samples $(\mathrm{n}=8)$ was extracted using a TRIzol ${ }^{\mathrm{TM}}$ Plus RNA Purification kit (Thermo Fisher Scientific, Inc., Waltham, MA, USA), according to the manufacturer's protocols. Subsequently, $300 \mathrm{ng}$ total RNA was used for further complementary DNA synthesis using a Vestar qPCR RT kit (cat. no. 2220; Deutsche Biotech Innovativ AG, Hennigsdorf, Germany), according to the manufacturer's protocols. qPCR was conducted in 3 wells for one sample using a $20-\mu 1$ reaction system $\left(\mathrm{SYBR}^{\circledR}\right.$ Green Realtime PCR Master Mix; cat.no. QPK-201; Toyobo Life Science, Osaka, Japan). The reaction was performed at $95^{\circ} \mathrm{C}$ for $15 \mathrm{~min}$, followed by 40 cycles at $95^{\circ} \mathrm{C}$ for $15 \mathrm{sec}$ and $60^{\circ} \mathrm{C}$ for $60 \mathrm{sec}$. The experiment was repeated three times. Relative mRNA expression was calculated with the comparative $2^{-\Delta \Delta \mathrm{Cq}}$ method (7) and GAPDH was used as the control. All primers were synthesized by Invitrogen (Thermo Fisher Scientific, Inc., Waltham, MA, USA). The primer sequences used in the qPCR were as follows: APLP2 forward, 5'-ACAGGATTT GCTGTTGCTGAG-3', and reverse, 5'-AGTGCCATGGAA CTGGTCTAC-3'; and GAPDH forward, 5'-CGGATTTGG TCGTATTGGG-3', and reverse, 5'-CTGGAAGATGGTGAT GGGATT-3'.

Immunohistochemical staining. The procedures for the immunohistochemical staining of tissue samples have been previously described (4). In brief, tissues were fixed in $4 \%$ polyformaldehyde at room temperature for $24 \mathrm{~h}$, and then embedded in paraffin wax and cut into sections of $3 \mu \mathrm{m}$ in thickness. The paraffin-embedded sections of cancer tissues were subsequently deparaffinized and heated in a pressure pot $\left(95^{\circ} \mathrm{C}\right)$ for $3 \mathrm{~min}$ to retrieve the antigens, were washed three times with xylene for $5 \mathrm{~min}$ and were rehydrated in a descending alcohol series (absolute ethanol, 95, 85 and 75\%). Subsequently, the sections were incubated in a 1:500 dilution of rabbit anti-APLP2 antibody (cat. no. ab128603; Abcam, Cambridge, UK) overnight at $4^{\circ} \mathrm{C}$. Antibody binding was detected using a peroxidase-conjugated secondary antibody (SPN-9001; goat anti-rabbit, ZSJQB Co., Ltd. Beijing, China) in a $1: 1,000$ dilution at $37^{\circ} \mathrm{C}$ for $30 \mathrm{~min}$. The sections were then stained with DAB Substrate kit (cat. no. ZLI9017; ZSJQB Co., Ltd.), according to the manufacturer's protocols, for $2 \mathrm{~min}$, and with hematoxylin for $2 \mathrm{~min}$ at room temperature. The expression of APLP2 in the tissues was observed under an optical microscope (DP72; Olympus Corporation, Tokyo, Japan) at x200 magnification.

The protein expression of APLP2 in the tissues was quantified by the intensity and extent of staining. The intensity of the staining was evaluated using the following criteria: 0 , negative; 1 , low; 2, medium; and 3, high. The extent of staining was scored as $0,0 \%$ stained; $1,1-25 \%$ stained; $2,26-50 \%$ stained; and $3,51-100 \%$ stained. The total expression of APLP 2 protein was calculated by multiplying the staining intensity score with the extent score. APLP2 was considered to be underexpressed when the result of this computation was $<6$.

Western blot analysis. The paired specimens $(\mathrm{n}=10)$ were homogenized in an ice-cold radioimmunoprecipitation assay buffer (cat. no. AR0105; Wuhan Boster Biological Technology, Ltd., Wuhan, China) containing $1 \mathrm{mM}$ phenylmethylsulfonyl fluoride to extract the tissue proteins in $4^{\circ} \mathrm{C}$ for $30 \mathrm{~min}$. A bicinchoninic acid assay kit (cat. no. BPT0001; BioRike; Changsha Dalfeng Biotechnology Co., Ltd., Changsha, China) was used to measure total protein concentrations, followed by western blot analysis as previously described (4). Briefly, denaturing $10 \%$ SDS-PAGE was used to separate $60 \mathrm{mg}$ protein, which was then transferred onto a polyvinylidene fluoride (PVDF) membrane electrophoretically. The PVDF membrane was blocked for $1 \mathrm{~h}$ at room temperature with $5 \%$ non-fat milk with Tris-buffered saline Tween-20 (TBST) dilution and then incubated with the aforementioned rabbit anti-APLP2 antibody (1:1,000 dilution) or $\beta$-actin antibody (1:1,000 dilution; cat. no. BM0627; Wuhan Boster Biological Technology, Ltd.) overnight at $4^{\circ} \mathrm{C}$. The membrane was then washed with TBST three times and incubated with horseradish peroxidase-conjugated goat anti-rabbit secondary antibodies at a dilution of 1:2,000 at room temperature (cat. no. BA1054; Wuhan Boster Biological Technology, Ltd.) for $2 \mathrm{~h}$. Finally, the protein bands were detected using a super enhanced chemiluminescence plus detection reagent (cat. no. EK1002; Wuhan Boster Biological Technology, Ltd.).

Statistical analysis. The association between the expression of APLP2 and the survival time of patients with RCC was analyzed by the Kaplan-Meier method with the log-rank test. Each experiment was performed in triplicate, and the values were presented as the mean \pm standard deviation, unless otherwise stated. The two-tailed Pearson's $\chi^{2}$ and Fisher's exact tests were used to compare categorical variables. A multivariate analysis was performed using the multivariate Cox proportional hazards model. Additionally, a paired Student's t-test was performed for investigating differences between two groups. Data analyses were performed using SPSS 22.0 (IBM Corp., Armonk, NY, USA) and P $<0.05$ was considered to indicate a statistically significant difference.

\section{Results}

Downregulation of APLP2 in human CCRCC tissues. The mRNA levels of APLP2 in 8 human CCRCC and adjacent tissues were measured by RT-qPCR. In 5/8 (62.5\%) tissue pairs, the mRNA level of APLP2 in the RCC tissues was reduced compared with that of the adjacent normal tissues (Fig. 1A). The paired Student's t-test data analysis demonstrated that the mRNA level of APLP2 was significantly reduced in the CCRCC tissues compared with that in the adjacent normal tissues (Fig. 1B; $\mathrm{P}=0.02$ ).

Downregulation of APLP2 in human RCC tissues. The levels of APLP2 protein in 10 human CCRCC and adjacent tissues were measured by western blot analysis. In 8/10 pairs of samples, the protein level of APLP2 was observed to be reduced in the CCRCC tissues compared with that in the adjacent normal tissues (Fig. 2). 

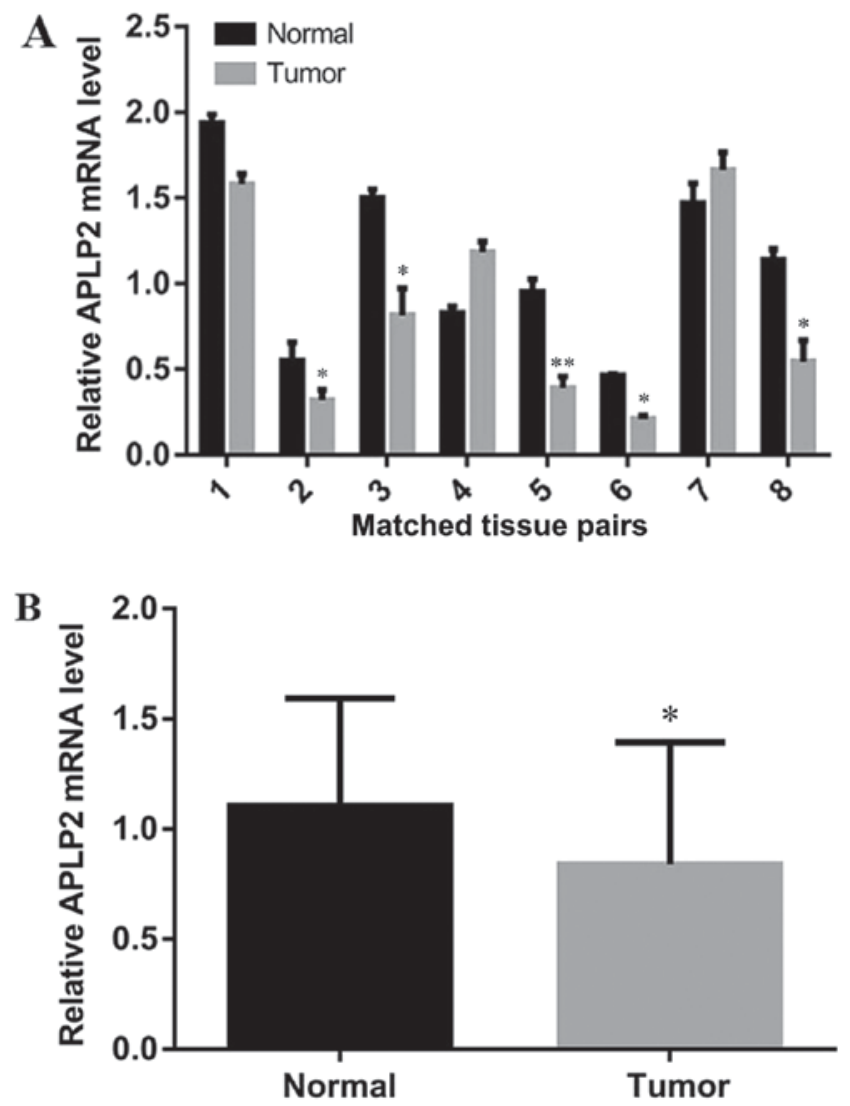

Figure 1. mRNA expression of APLP2 in normal and CCRCC tissues, as detected by reverse transcription-quantitative polymerase chain reaction. (A) APLP2 mRNA levels in 8 pairs of tissues. (B) Significantly decreased expression of APLP2 in CCRCC tissues $(\mathrm{P}=0.02)$. CCRCC, clear cell renal cell carcinoma; APLP2, amyloid $\beta$ precursor-like protein $2 .{ }^{*} \mathrm{P}<0.05$, "* $\mathrm{P}<0.01$, compared with normal.

Clinicopathological features and APLP2 expression. Randomly selected expression profiles of APLP2 in RCC and adjacent normal renal cortical tissues are depicted in Fig. 3. The expression of APLP2 protein in normal kidney tissues indicated a score $>6$ (Fig. 3A), CCRCC tissues indicated a score $<6$ (Fig. 3B), CCRCC tissues a score $>6$ (Fig. 3C) and in normal kidney tissues a score $<6$ Fig. 3D). The clinicopathologic characteristics of 90 patients are indicated in Table I. In detail, the expression of APLP2 was significantly associated with Fuhrman grade $(\mathrm{P}=0.018)$, pT stage $(\mathrm{P}=0.033)$, and the presence of distant metastasis $(\mathrm{P}=0.018)$ and lymph node metastasis $(\mathrm{P}=0.037)$. Pathological $\mathrm{T}$ stages was evaluated in accordance with the World Health Organization 1973 guidelines (8), and tumor grade according to Fuhrman et al (9). Additionally, there was no significant association between APLP2 expression and the sex or age of the patients, and the size of the renal tumor.

Survival analyses. Survival analyses were performed using the tissues and the follow-up information from well-documented patients. The Kaplan-Meier disease-specific survival curves were constructed using the scores of APLP2 expression. According to the results from the log-rank test, the expression of APLP2 was signicantly associated with disease-specific survival ( $\mathrm{P}<0.001 ;$ Fig. 4). Additionally, according to the results from the univariate analysis, age ( $>65$ years), high Fuhrman

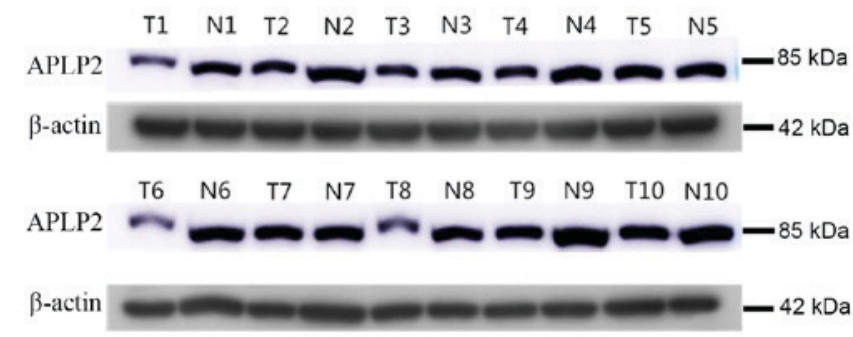

Figure 2. APLP2 protein expression in clear cell renal cell carcinoma and matched normal kidney samples. T, tumor sample; $\mathrm{N}$, matched normal sample; APLP2, amyloid $\beta$ precursor-like protein 2 .

grade $(\mathrm{P}=0.018)$, high $\mathrm{pT}$ stage $(\mathrm{P}=0.033)$, and the presence of lymph node $(\mathrm{P}=0.037)$ and distant metastasis $(\mathrm{P}=0.018)$ were also significant predictors of survival. However, sex and tumor size $(>7 \mathrm{~cm})$ were not significant predictors of survival (Table II). The subsequent multivariate Cox analysis demonstrated that the increased expression of APLP2 was an independent predictor of disease-specific survival $(\mathrm{P}=0.026)$. Additionally, age ( $>65$ years), high pT stage, and presence of distant and lymph node metastasis were independent predictors. However, high Fuhrman grade was not a significant independent predictor (Table II).

\section{Discussion}

A previous study demonstrated that APLP2 expression is aberrantly altered in a number of cancer types (6). However, there is limited knowledge regarding the expression of APLP2 in RCC, including the association between the expression of APLP2 and the prognosis of the disease. In the present study, the association between APLP2 and the pathological and prognostic features of CCRCC was examined. It was determined that the mRNA and protein levels of APLP2 were significantly decreased in RCC tissues compared with those in matched normal tissues. The expression of APLP2 was associated with the Fuhrman grade and pT stage of CCRCC. Subsequently, the survival analysis demonstrated that low expression of APLP2 was an independent predictor of disease-specific survival.

Data from the present study indicated that APLP2 may be a cancer suppressor gene in CCRCC. A previous study also reported that APLP2 was notably downregulated in neuroendocrine lung tumor cases (10). However, a number of studies demonstrated that the expression of APLP2 was significantly increased in other cancer types, including breast cancer (11), pancreatic cancer (12), myeloid leukaemia (13) and testicular germ cell tumors (14). Furthermore, the reason for the different expression of APLP2 in different cancer types remains unclear. This difference may be due to different pathogeneses in different cancer types. Additionally, this phenomenon may account for the different mechanisms of carcinogenesis in different cancer types (15). In addition, a previous study indicated that splicing may result in its gene diversity, and the different expression profiles and functions of APLP2 in different tissues (16). The results of the present study also demonstrated that APLP2 may serve different roles in different tissues. 
A

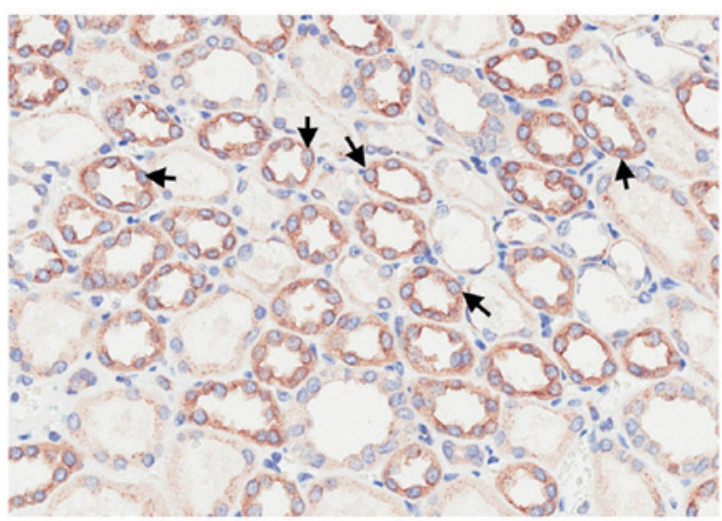

B

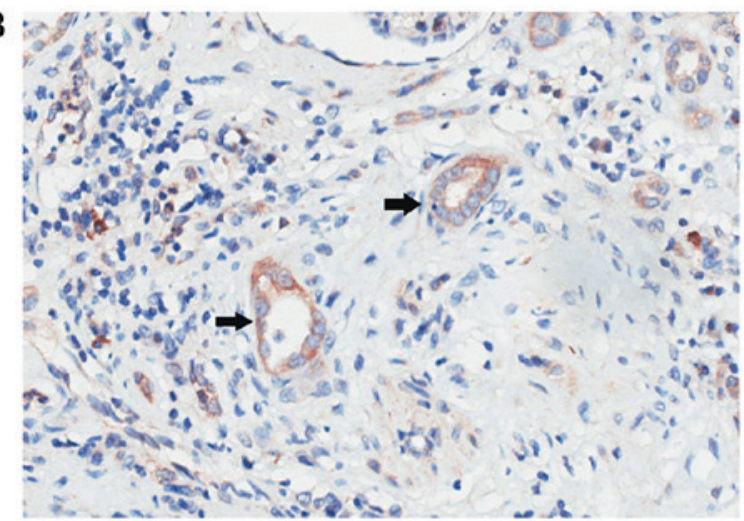

C

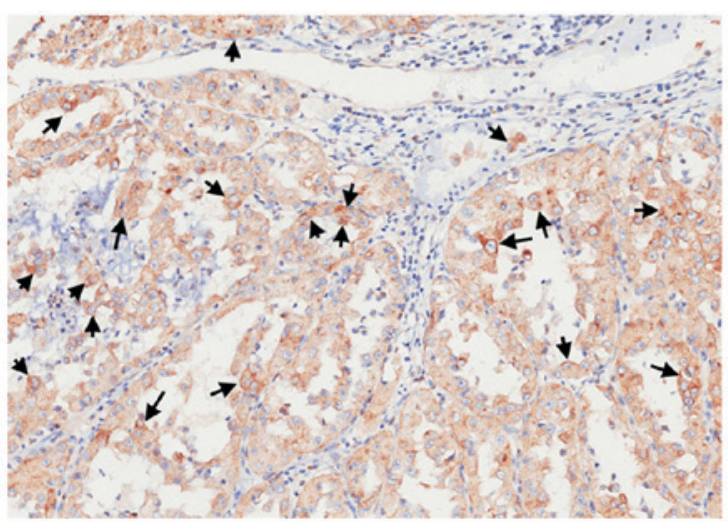

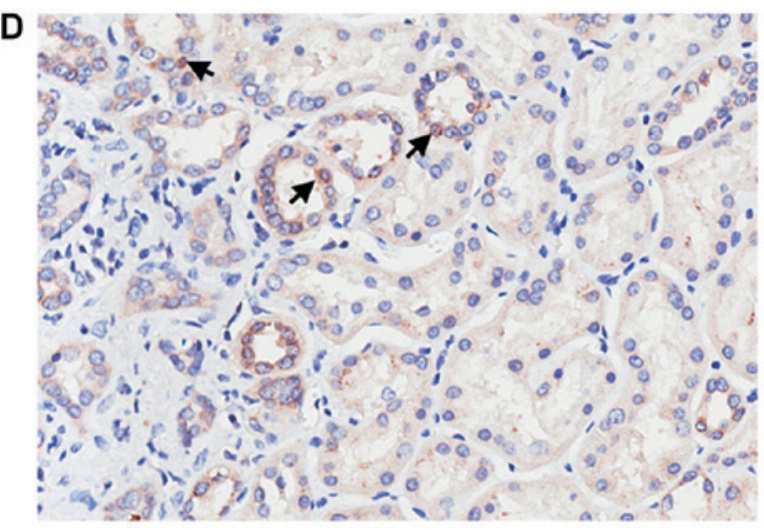

Figure 3. Expression of APLP2 protein observed by immunohistochemical staining. The arrows point to cells with a positive staining of APLP2. (A) Expression of APLP2 protein in normal kidney tissues (score >6). (B) Expression of APLP2 protein in CCRCC tissues (score <6). (C) Expression of APLP2 protein in CCRCC tissues (score >6). (D) Expression of APLP2 protein in normal kidney tissues (score <6). Magnification, x200. CCRCC, clear cell renal cell carcinoma; APLP2, amyloid $\beta$ precursor-like protein 2 .

APLP2 has been associated with certain characteristics of cancer cells, including pro-growth and pro-invasion functions (5); however, the specific role of APLP2 in cancer cell development and progression remains unclear. At present, the signalling pathways by which APLP2 wields its effects in cancer cells are poorly understood. Pandey et al (5) determined that loss of APLP2 decreased cortical actin and increased intracellular actin filaments in pancreatic cancer cells, reducing the ability of these cells to migrate and invade. Other studies demonstrated that APLP2 can regulate major histocompatibility complex class I molecule expression in cancer cells and increase cancer immune evasion $(17,18)$. There is further research required in order to determine the biological activity of APLP2 in cancer cells. In the present study, APLP2 exhibited significantly reduced expression in tissues from patients with CCRCC, and this information indicated that APLP2 may serve as a suppressor in CCRCC. However, further studies are required to investigate the specific role of APLP2 in RCC.

There are a number of limitations in the present study. Firstly, all tissue samples were collected from one region, which may result in bias. Secondly, the sample size in the present study was relatively small and further larger studies on APLP2 in CCRCC are required in the future. Finally, APLP2 was determined to serve as a potential suppressor of RCC, but its underlying mechanism has not been investigated. In particular, since mutations of the von Hippel-Lindau (VHL) tumor suppressor gene are considered as drivers of

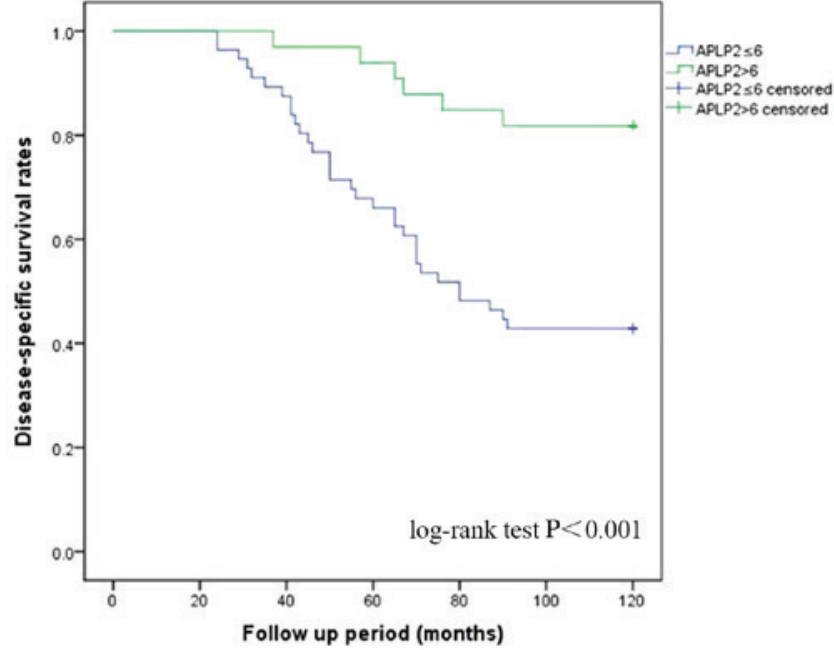

Figure 4. Kaplan-Meier survival curves of APLP2 expression in clear cell renal cell carcinoma tissues. Patients with low expression of APLP2 exhibited reduced disease-specific survival rates, compared with patients with high expression of APLP2. $\mathrm{P}<0.001$. APLP2, amyloid $\beta$ precursor-like protein 2 .

CCRCC (19), whether APLP2 is associated with VHL remains unknown.

In conclusion, the present study provided initial evidence that APLP2 is downregulated in CCRCC and is associated with certain pathological features of CCRCC. The results 
Table I. Clinicopathological features and their associations with APLP2 expression.

\begin{tabular}{|c|c|c|c|c|}
\hline \multirow[b]{2}{*}{ Variables } & \multirow[b]{2}{*}{ Total cases $(n=90)$} & \multicolumn{2}{|c|}{$\begin{array}{c}\text { APLP2 expression } \\
\text { level }\end{array}$} & \multirow[b]{2}{*}{ P-value } \\
\hline & & $<6$ & $\geq 6$ & \\
\hline Tissues & & & & $0.003^{\mathrm{a}}$ \\
\hline Tumor tissues & 90 & 37 & 53 & \\
\hline Normal tissues & 90 & 57 & 33 & \\
\hline Age (years) & & & & 0.866 \\
\hline$\leq 65$ & 59 & 37 & 22 & \\
\hline$>65$ & 31 & 20 & 11 & \\
\hline Sex & & & & 0.65 \\
\hline Male & 49 & 30 & 19 & \\
\hline Female & 41 & 27 & 14 & \\
\hline Fuhrman grade & & & & $0.018^{\mathrm{a}}$ \\
\hline I-II & 48 & 25 & 23 & \\
\hline III-IV & 42 & 32 & 10 & \\
\hline Tumor size (longest diameter, $\mathrm{cm}$ ) & & & & 0.31 \\
\hline$\leq 7$ & 51 & 30 & 21 & \\
\hline$>7$ & 39 & 27 & 12 & \\
\hline Lymph node metastasis & & & & $0.037^{\mathrm{a}}$ \\
\hline Absence & 73 & 42 & 31 & \\
\hline Presence & 17 & 15 & 2 & \\
\hline Distant metastasis & & & & $0.018^{\mathrm{a}}$ \\
\hline Absence & 79 & 46 & 33 & \\
\hline Presence & 11 & 11 & 0 & \\
\hline pT stage & & & & $0.033^{\mathrm{a}}$ \\
\hline T1-T2 & 71 & 41 & 30 & \\
\hline T3-T4 & 19 & 16 & 3 & \\
\hline
\end{tabular}

${ }^{\mathrm{a}} \mathrm{P}<0.05$. APLP2, amyloid $\beta$ precursor-like protein 2 .

Table II. Cox regression analyses for disease-specific survival.

\begin{tabular}{|c|c|c|c|c|}
\hline & \multicolumn{2}{|c|}{ Univariate analysis } & \multicolumn{2}{|c|}{ Multivariate analysis } \\
\hline & $\mathrm{HR}(95 \% \mathrm{CI})$ & P-value & HR $(95 \%$ CI $)$ & P-value \\
\hline Age (>65 years) & $0.281(0.146-0.540)$ & $<0.001^{\mathrm{a}}$ & $6.454(2.887-14.427)$ & $<0.001^{\mathrm{a}}$ \\
\hline Sex female & $1.072(0.146-2.025)$ & 0.830 & $0.819(0.356-1.887)$ & 0.640 \\
\hline Grade high (III-IV) & $0.490(0.255-0.945)$ & $0.033^{\mathrm{a}}$ & $0.845(0.372-1.921)$ & 0.687 \\
\hline Tumor size (>7 cm) & $1.227(0.648-2.323)$ & 0.530 & $0.452(0.200-1.018)$ & 0.055 \\
\hline pT high (T3-T4) & $0.112(0.057-0.222)$ & $<0.001^{\mathrm{a}}$ & $3.380(1.375-8.307)$ & $0.008^{\mathrm{a}}$ \\
\hline Lymph node metastasis & $0.122(0.061-0.244)$ & $<0.001^{\mathrm{a}}$ & $2.584(1.126-5.929)$ & $0.025^{\mathrm{a}}$ \\
\hline Distant metastasis & $0.140(0.067-0.292)$ & $<0.001^{\mathrm{a}}$ & $4.131(1.431-11.928)$ & $0.009^{\mathrm{a}}$ \\
\hline APLP2 score $\leq 6$ & $4.401(1.837-10.545)$ & $0.001^{\mathrm{a}}$ & $3.138(1.148-8.581)$ & $0.026^{\mathrm{a}}$ \\
\hline
\end{tabular}

${ }^{a} \mathrm{P}<0.05$. HR, hazard ratio; CI, confidence interval; APLP2, amyloid $\beta$ precursor-like protein 2.

also demonstrated that APLP2 expression is significantly and independently associated with the disease-specific survival of patients with RCC. The measurement of APLP2 levels may therefore assist in improving the accuracy of RCC diagnosis, particularly CCRCC, to evaluate the therapeutic efficacy of treatment, and to predict prognosis. Further efforts are required 
to clarify the precise molecular mechanism of APLP2 in the occurrence, progression and metastasis of CCRCC.

\section{Acknowledgements}

Not applicable.

\section{Funding}

The present study was supported by the Key Research and Development Grants of Shandong Province, China (grant no., 2016GSF201011).

\section{Availability of data and materials}

The datasets used or analysed during the present study are available from the corresponding author on reasonable request.

\section{Authors' contributions}

BS designed the project and performed study supervision. LG and $\mathrm{HZ}$ designed the project and performed the development of the methodology. DZ, CZ, YL, HW, CR and YX collected, analyzed and interpreted the data. YL and YX contributed to drafting the manuscript.

\section{Ethics approval and consent to participate}

The present study was approved by the Medical Ethics Committee of Qilu Hospital of Shandong University. Written informed consent was obtained from all patients.

\section{Patient consent for publication}

The study has obtained consents from all patient for publication.

\section{Competing interests}

The authors declare that they have no conflicts of interest.

\section{References}

1. Siegel RL, Miller KD and Jemal A: Cancer Statistics, 2017. CA Cancer J Clin 67: 7-30, 2017.

2. Barata PC and Rini BI: Treatment of renal cell carcinoma: Current status and future directions. CA Cancer J Clin 67: 507-524, 2017.

3. Muller UC, Deller T and Korte M: Not just amyloid: Physiological functions of the amyloid precursor protein family. Nat Rev Neurosci 18: 281-298, 2017.
4. Shariati SA and De Strooper B: Redundancy and divergence in the amyloid precursor protein family. FEBS Lett 587: 2036-2045, 2013.

5. Pandey P, Rachagani S, Das S, Seshacharyulu P, Sheinin Y, Naslavsky N, Pan Z, Smith BL, Peters HL, Radhakrishnan P, et al: Amyloid precursor-like protein 2 (APLP2) affects the actin cytoskeleton and increases pancreatic cancer growth and metastasis. Oncotarget 6: 2064-2075, 2015.

6. Pandey P, Sliker B, Peters HL, Tuli A, Herskovitz J, Smits K, Purohit A, Singh RK, Dong J, Batra SK, et al: Amyloid precursor protein and amyloid precursor-like protein 2 in cancer. Oncotarget 7: 19430-19444, 2016.

7. Livak KJ and Schmittgen TD: Analysis of relative gene expression data using real-time quantitative PCR and the 2(-Delta Delta C (T)) method. Methods 25: 402-408, 2001.

8. Edge SB and Compton CC: The American Joint Committee on Cancer: the 7th edition of the AJCC cancer staging manual and the future of TNM. Ann Surg Oncol 17:1471-1474, 2010.

9. Fuhrman SA, Lasky LC and Limas C: Prognostic significance of morphologic parameters in renal cell carcinoma. Am J Surg Pathol 6: 655-663, 1982.

10. Arvidsson Y, Andersson E, Bergström A, Andersson MK, Altiparmak G, Illerskog AC, Ahlman H, Lamazhapova D and Nilsson O: Amyloid precursor-like protein 1 is differentially upregulated in neuroendocrine tumours of the gastrointestinal tract. Endocr Relat Cancer 15: 569-581, 2008.

11. Lim S, Yoo BK, Kim HS, Gilmore HL, Lee Y, Lee HP, Kim SJ, Letterio J and Lee HG: Amyloid-beta precursor protein promotes cell proliferation and motility of advanced breast cancer. BMC Cancer 14: 928, 2014.

12. Peters HL, Tuli A, Wang X, Liu C, Pan Z, Ouellette MM, Hollingsworth MA, Macdonald RG and Solheim JC: Relevance of amyloid precursor-like protein $2 \mathrm{C}$-terminal fragments in pancreatic cancer cells. Int J Oncol 41: 1464-1474, 2012.

13. Jiang L, Yu G, Meng W, Wang Z, Meng F and Ma W: Overexpression of amyloid precursor protein in acute myeloid leukemia enhances extramedullary infiltration by MMP-2. Tumour Biol 34: 629-636, 2013.

14. Venkataramani V, Thiele K, Behnes CL, Wulf GG, Thelen P, Opitz L, Salinas-Riester G, Wirths O, Bayer TA and Schweyer S: Amyloid precursor protein is a biomarker for transformed human pluripotent stem cells. Am J Pathol 180: 1636-1652, 2012.

15. Cojocaru E, Lozneanu L, Giusccă SE, Căruntu ID and Danciu M: Renal carcinogenesis-insights into signaling pathways. Rom J Morphol Embryol 56: 15-19, 2015.

16. Sandbrink R, Masters CL and Beyreuther K: Similar alternative splicing of a non-homologous domain in beta A4-amyloid protein precursor-like proteins. J Biol Chem 269: 14227-14234, 1994.

17. Meng JY, Kataoka H, Itoh $\mathrm{H}$ and Koono M: Amyloid beta protein precursor is involved in the growth of human colon carcinoma cell in vitro and in vivo. Int J Cancer 92: 31-39, 2001.

18. Peters HL, Tuli A, Sharma M, Naslavsky N, Caplan S, MacDonald RG and Solheim JC: Regulation of major histocompatibility complex class I molecule expression on cancer cells by amyloid precursor-like protein 2 . Immunol Res 51: 39-44, 2011.

19. Mehdi A and Riazalhosseini Y: Epigenome aberrations: Emerging driving factors of the clear cell renal cell carcinoma. Int J Mol Sci 18: E1774, 2017. 